\title{
User-Acceptance and Flow in Two Gaming Platforms Used for Exercise
}

\author{
Jonathan Robinson MSc, BSc (Hons) \\ Centre for Rehabilitation Sciences \\ School of Health and Social Care \\ Teesside University \\ Middlesbrough, England \\ J.Robinson@tees.ac.uk
}

\author{
Prof. Paul van Schaik, Dr Alasdair MacSween, \\ Dr John Dixon and Prof. Denis Martin, \\ Centre for Rehabilitation Sciences \\ School of Health and Social Care \\ Teesside University \\ Middlesbrough, England
}

\begin{abstract}
The aim of this study was to compare users' acceptance and experience through psychological questionnaires for two gaming platforms when used as an exercise tool. Thirty-three participants were recruited from the population of Teesside University, UK. Participants were randomly allocated to either exercise using the Interactive Rehabilitation and Exercise system, or the Nintendo Wii. Following a four-week exercise programme, no significant differences were found between gaming platforms. However, there were significant increases in acceptance and experience.
\end{abstract}

Key words: Virtual Reality; Exercise; IREX; Nintendo Wii.

\section{INTRODUCTION}

Gaming technology is becoming increasingly recognised for its potential as a rehabilitation tool [1]. For example, it has been applied in clinical use for stroke [2] and cerebral palsy [3] rehabilitation, as well as a means of general exercise in healthy subjects [4]. Gaming platforms are marketed as providing an attractive environment for exercise. Given that patients' preference for the type of exercise is an important factor in the success of exercise therapy in rehabilitation it is important to know how people interact with different platforms and what influences this interaction. In particular we are interested in users' acceptability of such platforms for exercise and in their flow experience (absorption in the activity) during their use. This study aims to compare the potential of two different gaming platforms for rehabilitation by comparing users' acceptance and flow experience of people who have used them for balance training.

\section{METHOD}

This study employed an experimental design with a between-subject factor and a within-subject factor. The between-subject factor was exercise system, IREX ${ }^{\mathrm{TM}}$ and Nintendo Wii ${ }^{\mathrm{TM}}$. The within-subjects factor was time with two levels - the start of the four week exercise programme (baseline) and the end of the programme (post-programme). Participants were randomly allocated into either the IREX ${ }^{\mathrm{TM}}$ group or the Nintendo Wii ${ }^{\mathrm{TM}}$ group. Ethical approval was granted by Teesside University School of Health and Social Care Research and Governance Committee.

\section{A. Participants}

A convenience sample was recruited from staff and students in Teesside University. Inclusion criteria were healthy men and women, aged 18-65 years, leading a predominantly sedentary life style, defined as undertaking less than 30 minutes of moderate exercise most weeks [5]. Exclusion criteria were musculoskeletal injury or other major health condition, and inability to follow instructions. Thirty-three participants (25 females and 8 males) were recruited. Participant details are shown in Table I.

TABLE I. DETAILS OF PARTICIPANTS

\begin{tabular}{|c|c|c|}
\cline { 2 - 3 } \multicolumn{1}{c|}{} & Wii $(\mathbf{n}=\mathbf{1 7})$ & IREX $(\mathbf{n}=\mathbf{1 6})$ \\
\hline Age mean (1SD) (years) & $27.7(7.5)$ & $29.7(9.0)$ \\
\hline Mass mean (1SD) (kg) & $65.12(15.36)$ & $62.5(11.04)$ \\
\hline Men/Women & $4 / 13$ & $4 / 12$ \\
\hline
\end{tabular}

\section{B. Instrumentation}

Users' acceptance was measured (on a 1-7 point scale, 1 strongly disagree, 7 - strongly agree) using the adapted Unified Theory of Acceptance and Use of Technology (UTAUT) questionnaire [6]. This has 22 items categorized into 6 subscales - Performance Expectancy (PE), Effort Expectancy (EE), Social Influences (SI), Facility Conditions (FC), Selfefficacy (SE), and Behavioural Intention (BI; Intention to Use).

Flow experience was measured (on a 1-5 point scale 1 strongly disagree, 5 - strongly agree) using the Flow State Scale [7]. The 36 item questionnaire consists of 9 subscales Autotelic Experience (AE), Clear Goals (CG), Challenge-Skill Balance (CB), Concentration of Task (CT), Paradox of Control (PC), Unambiguous Feedback (UF), Action-Awareness Merging (AM), Transformation of Time (TT), and Loss of SelfConsciousness (LS).

\section{Procedure}

This study was undertaken in a laboratory at Teesside University. In both groups the exercise sessions comprised 12 individual sessions over a period of 4 weeks, with each session consisting of approximately 20-30 minutes of actual exercise completed under supervision of the primary researcher. The questionnaires were completed at the beginning (baseline) and end (post-programme) of the exercise programme.

\section{STATISTICAL ANALYSIS}

Statistical analysis was performed using Statistical Package for the Social Sciences Version 18 for Windows (SPSS, Chicago, IL, USA). For each subscale of the two questionnaires 
a separate analysis of covariance, with baseline scores as a covariate, and platform (IREX ${ }^{\mathrm{TM}}$ and Wii ${ }^{\mathrm{TM}}$ ) type as a fixed factor, was used to analyze for differences between groups postprogramme. Within subject differences between baseline and post-programme scores for each subscale were analysed using mixed ANOVA. In an exploratory analysis, multiple regression was used to investigate influences on future use of the platforms for exercise. The UTAUT subscale of Behavioural Intention was used as the dependent variable and the other subscales were used as predictors, and data for both platforms were combined.

\section{RESULTS}

Means and Standard Deviations (1SD) for each subscale of the UTAUT questionnaire are shown in Table II.

TABLE II. MEANS (1SD) FOR SUBSCALES OF UNIFIED THEORY OF ACCEPTANCE AND USE OF TECHNOLOGY QUESTIONNAIRE

\begin{tabular}{|c|l|c|c|c|c|c|}
\hline \multicolumn{7}{|c|}{ Baseline } \\
\hline Platform & PE & EE & FC & SE & BI \\
\hline \multirow{3}{*}{ Wii } & Mean & 5.24 & 5.56 & 4.90 & 5.00 & 5.47 \\
\cline { 2 - 7 } & SD & 1.16 & 1.40 & 0.96 & 1.48 & 1.78 \\
\hline \multirow{3}{*}{ IREX } & Mean & 4.78 & 5.53 & 4.67 & 5.23 & 5.29 \\
\cline { 2 - 7 } & SD & 1.39 & 0.78 & 1.02 & 1.27 & 1.34 \\
\hline \multirow{7}{*}{ Post-Programme } \\
\hline \multirow{2}{*}{ Wlatform } & Mean & 5.71 & 5.85 & 5.65 & 5.38 & 5.31 \\
\cline { 2 - 7 } & SD & 1.07 & 1.67 & 1.39 & 1.68 & 1.88 \\
\hline \multirow{2}{*}{ IREX } & Mean & 5.36 & 6.11 & 5.85 & 5.72 & 5.58 \\
\cline { 2 - 7 } & SD & 1.03 & 1.15 & 0.84 & 1.49 & 1.34 \\
\hline
\end{tabular}

There were no significant differences post-programme between groups for any of the subscales of the questionnaire. However, there were between pre- and post-test values. A mixed ANOVA documented that the effect of time (Baseline and Post-Programme) was significant for PE $p<0.01$, EE $p<$ 0.01 , FC $p<0.01$, and SE $p=0.03$ but not for BI $(p=0.65)$. None of the interaction effects were significant. All significant subscales indicated a significant increase from baseline to those at post-programme.

Using standard multiple regression analysis to predict $\mathrm{BI}$, a model emerged for pre-intervention measures $\left(F_{3,32}=5.55, p<\right.$ 0.01). A model was also found for post-intervention measures $\left(F_{3,32}=4.66, p<0.05\right)$. FC was a significant predictor at baseline. Both FC and PE were significant predictors after completion of the programme (see Table III).

TABLE III. Multiple REGRESSION MODEL FOR BEHAVIOURAL INTENTION

\begin{tabular}{|l|c|c|c|c|c|c|}
\hline Predictors & \multicolumn{3}{|c|}{ Baseline } & \multicolumn{3}{c|}{ Post-Programme } \\
\hline & B & SE B & $\beta$ & B & SE B & $\beta$ \\
\hline Constant & -0 & 1.45 & & -0.3 & 1.57 & \\
\hline PE & 0.27 & 0.21 & 0 & 0.6 & 0.28 & $0.39^{* *}$ \\
\hline FC & 0.71 & 0.26 & $0.44^{*}$ & 0.63 & 0.28 & $0.45^{* *}$ \\
\hline EE & 0.12 & 0.24 & 0 & -0.2 & 0.25 & -0 \\
\hline $\mathbf{R}^{2}$ & 0.36 & & & 0.33 & & \\
\hline Adjusted $\mathbf{R}^{\mathbf{2}}$ & 0.3 & & & 0.26 & & \\
\hline
\end{tabular}

Note: $* \mathrm{p}<0.01, * * \mathrm{p}<0.05$

\section{Flow Experience}

Means and Standard Deviations (1SD) for each subscale of the Flow State Scale are shown in Table IV.

There were no significant differences post-programme between groups for any of the subscales. However, there were significant changes over time. The effect of time (Baseline to Post-Programme) was significant for AE $p<0.01$, CG $p<0.01$, CB $p<0.01$, CT $p<0.01$, PC $p<0.01$, UF $p<0.01$, AM $p<$ 0.01 , and TT $p<0.01$, but not for LS $(p=0.07)$. None of the interaction effects were significant. All significant subscale differences indicate a significant increase from baseline to postprogramme.

TABLE IV. MEANS (1SD) FOR SUbSCALES OF Flow State SCALE

\begin{tabular}{|c|l|c|c|c|c|c|c|c|c|c|}
\hline \multicolumn{10}{|c|}{ Baseline } \\
\hline \multicolumn{1}{|l|}{ Platform } & AE & CG & CB & CT & PC & UF & AM & TT & LF \\
\hline \multirow{2}{*}{ Wii } & Mean & 3.91 & 3.97 & 3.63 & 4.08 & 3.53 & 3.68 & 2.90 & 2.65 & 3.90 \\
\cline { 2 - 12 } & SD & 1.03 & 0.93 & 0.72 & 1.01 & 0.97 & 0.90 & 0.88 & 1.36 & 1.11 \\
\hline \multirow{2}{*}{ IREX } & Mean & 3.77 & 3.98 & 3.80 & 3.98 & 3.41 & 3.67 & 3.09 & 2.88 & 3.94 \\
\cline { 2 - 11 } & SD & 0.72 & 0.74 & 0.78 & 0.69 & 1.01 & 0.69 & 0.60 & 0.89 & 0.79 \\
\hline \multicolumn{10}{|c|}{ Post-Programme } \\
\hline \multirow{2}{*}{ Platform } & AE & CG & CB & CT & PC & UF & AM & TT & LF \\
\hline \multirow{2}{*}{ Wii } & Mean & 4.18 & 4.34 & 3.99 & 4.30 & 3.91 & 4.04 & 3.41 & 3.03 & 4.13 \\
\cline { 2 - 11 } & SD & 1.09 & 0.88 & 0.83 & 0.68 & 1.01 & 1.02 & 0.93 & 1.40 & 1.04 \\
\hline \multirow{2}{*}{ IREX } & Mean & 4.09 & 4.46 & 4.41 & 4.54 & 4.21 & 4.30 & 3.75 & 3.45 & 4.32 \\
\cline { 2 - 10 } & SD & 0.93 & 0.65 & 0.68 & 0.63 & 0.74 & 0.76 & 0.71 & 1.07 & 1.01 \\
\hline
\end{tabular}

\section{DISCUSSION}

In this comparison of the users' acceptance and flow experience of people who had exercised using two different gaming platforms no significant differences were found between gaming platforms. However, in both conditions significant increases in user acceptance and flow were found having completed the four week programme. Furthermore, the results of an exploratory regression analyses indicate that Facility Conditions and Performance Expectancy are significant predictors of Behavioural Intention to use this technology. These factors should be considered when using this technology as a rehabilitation tool, as it may influence uptake and concordance.

\section{REFERENCES}

[1] Weiss, P.L., Rand, D., Katz, N. and Kizony, R. (2004) Video capture virtual reality as a flexible and effective rehabilitation tool, Journal of neuroengineering and rehabilitation, 1(1), 12.

[2] Brosnan, S. (2009) The Potential of Wii-Rehabilitation for Persons Recovering From Acute Stroke. Physical Disabilities, 32(1), 1-3.

[3] Deutsch, J.E., Borbely, M., Filler, J., Huhn, K. and GuarreraBowlby, P. (2008) Use of a Low-Cost, Commercially Available Gaming Console (Wii) for Rehabilitation of an adolescent With Cerebral Palsy, Physical Therapy, 88(10), 1196.

[4] White, K., Schofield, G., and Kilding, A. E. (2011) Energy expended by boys playing active video games, Journal of Science and Medicine in Sport, 14(2), 130-134.

[5] (ACSM). Guidelines for exercise testing and prescription, (2005) 7th edn.Philadelphia: Lippincott Williams \& Wilkins, ISBN 0-78174506-3.

[6] Venkatesh, V., Morris, M. G., Davis, G. B., and Davis, F. D. (2003) User acceptance of information technology: toward a unified view, MIS Quarterly, 27(3), 425-478.

[7] Jackson, S. A. and Marsh, H. W. (1996) Development of validation of a scale to measure optimal experience: The Flow State Scale, Journal of Sport \& Exercise Psychology, 18, 17-35. 